\title{
Arpp, a New Homolog of Carp, Is Preferentially Expressed in Type 1 Skeletal Muscle Fibers and Is Markedly Induced by Denervation
}

\author{
Yoshiyuki Tsukamoto, Takao Senda, Toshiya Nakano, Chisato Nakada, \\ Takehiko Hida, Naoko Ishiguro, Gento Kondo, Takeshi Baba, Kenzo Sato, \\ Mitsuhiko Osaki, Shigeo Mori, Hisao Ito, and Masatsugu Moriyama
}

Department of Molecular Biology (YT, CN, NI, GK, TB, KS, MM), Department of Neurology (TN), First Department of Pathology (MO, HI), Faculty of Medicine, Tottori University, Yonago; First Department of Anatomy (TS, TH), School of Medicine, Fujita Health University, Toyoake; and Department of Pathology (SM), Institute of Medical Science, University of Tokyo, Tokyo, Japan

\begin{abstract}
SUMMARY: In this study, we isolated and characterized a murine counterpart of the human Arpp (hArpp) gene. Sequence analysis revealed that the murine $\operatorname{Arpp}(m A r p p)$ gene is almost identical to the Ankrd2 gene, which has recently been isolated as a mouse gene induced in stretched skeletal muscle. The mArpp gene encodes a protein of 332 amino acids that contains four well-conserved ankyrin-repeat domains in the central portion of the protein. The amino acid sequence of mArpp protein (mArpp) is highly homologous to that of mouse cardiac-restricted ankyrin-repeat protein (Carp), which is proposed to be a putative genetic marker for cardiac hypertrophy. Immunohistochemical analysis revealed that mArpp is preferentially expressed in type 1 skeletal muscle fibers, and that mArpp is localized in both the nucleus and the sarcomeric l-band of muscle fibers, suggesting that Arpp may function as a nuclear and sarcomeric protein. Furthermore, mArpp was also expressed in neurons of the cerebellum and cerebrum, the islets of Langerhans in the pancreas, and the esophageal epithelium, suggesting that mArpp may play a functional physiologic role in brain, pancreas, and esophagus as well as in type 1 muscle fibers. Interestingly, although mArpp was localized in both nucleus and cytoplasm in neurons, its localization was restricted to nucleus in pancreas and esophagus, suggesting that intracellular localization of mArpp is regulated in a tissue-specific manner. Furthermore, we found that mArpp- and Carpexpression in skeletal muscle were markedly up-regulated after denervation. Although the elevated expression level of Carp was kept only for two weeks after denervation, that of Arpp was kept at least for 4 weeks, suggesting that mArpp and Carp may play distinct functional roles in denervated skeletal muscle. (Lab Invest 2002, 82:645-655).
\end{abstract}

$W$ e recently isolated a novel human gene, Arpp, which is strongly expressed in human skeletal and cardiac muscle (Moriyama et al 2001). The human Arpp ( $h$ Arpp) gene encodes a 43-kd protein (hArpp) composed of 333 amino acids (Moriyama et al 2001). The most characteristic structural feature of this protein is the presence of four ankyrin-repeat domains in its central portion. It also contains a lysine-rich region (KKRK) resembling a nuclear localization signal, and a PEST motif, in the $\mathrm{N}$-terminal region, and a prolinerich region in the $\mathrm{C}$-terminal region. The amino acid sequence of hArpp is highly homologous (52.2\%) to that of cardiac-restricted ankyrin-repeat protein (Carp) (Chu et al 1995; Jeyaseelan et al 1997; Zou et al 1997), and the structural features are well conserved between the two proteins. These similarities in structure

\section{Received February 15, 2002}

This work was supported in part by a grant-in-aid from the Ministry of Education of Japan, grant number 12877032.

Address reprint requests to: Dr. Masatsugu Moriyama, Department of Molecular Biology, School of Life Science, Faculty of Medicine, Tottori University, 86 Nishimachi, Yonago-city, Tottori 683-8503, Japan. E-mail:moriyama@grape.med.tottori-u.ac.jp suggest that Arpp and Carp may be members of the same protein family (Moriyama et al 2001). Carp was expressed in heart but rarely expressed in skeletal muscle (Zou et al, 1997). Furthermore, Carp expression is increased in a mouse model of concentric heart hypertrophy induced by pressure overload (Aihara et al, 2000; Kuo et al, 1999). Based on these findings, Carp is proposed to be a genetic marker for cardiac hypertrophy.

In this study, to further characterize the new Carp homolog, Arpp, we isolated a murine counterpart of the hArpp gene and analyzed the expression of its gene product. Comparison of the mouse Arpp (mArpp) gene with sequences in the DNA Data Bank of Japan (DDBJ) revealed that the mArpp gene was identical to the recently isolated mouse Ankrd2 gene, which is induced in stretched skeletal muscle (Kemp et al, 2000). Furthermore, we found that mArpp was preferentially expressed in type 1 skeletal muscle fibers, but it was not expressed in heart. Interestingly, we found that Arpp expression was significantly induced in denervated skeletal muscle. These findings suggest that Arpp may play some functional roles in type 1 muscle fibers under physiologic conditions, and 
that, when muscle fibers were denervated, mArpp may be induced to play some specific functional roles in denervated muscle.

\section{Results}

\section{Cloning of Full-Length mArpp cDNA}

To identify the murine counterpart of the hArpp gene, we screened $1.0 \times 10^{6} \mathrm{pfu}$ of a murine skeletal muscle cDNA library with hArpp cDNA as a probe. We isolated five positive clones after the third screening. Sequencing analysis revealed that the sequences of these five clones were identical to each other and highly homologous to that of hArpp cDNA (82.4\% identity). We have already published the sequences of the isolated cDNA in the DDBJ (accession no. AB079548). Next, to determine the precise transcriptional start site, cap site hunting was performed as described in "Materials and Methods." As shown in Figure 1, A and B, the first methionine was located $10 \mathrm{bp}$ downstream of the transcriptional start site. The first methionine of mArpp is likely to be the translational initiation codon, on the basis of the following findings: first, the first methionine of mArpp is conserved in hArpp; second, we confirmed in a previous study that translation of hArpp starts at the first methionine (Moriyama et al, 2001). As shown in Figure 1C, the amino acid sequence of mArpp exhibits significant homology to that of hArpp throughout the full length of the protein $(88.9 \%$ identity). The open reading frame of mArpp contains four ankyrin-repeat motifs in its middle portion, a lysinerich region in the $\mathrm{N}$-terminal region, $\mathrm{PEST}$ sequences in the $\mathrm{N}$ - and $\mathrm{C}$-terminal regions, and a proline-rich region (Fig. 1D). These structural features of $m A r p p$ are completely conserved in hArpp, except for another $\mathrm{PEST}$ sequence in the $\mathrm{C}$-terminal region. These results suggest that mArpp is highly likely to be a murine counterpart of hArpp.

\section{Structural Characterization of the mArpp Gene}

By screening $0.8 \times 10^{6}$ pfu of a mouse genomic library, three independent positive clones (clones $A, B$, and $C$ ) were isolated. Sequence analysis of these clones revealed that the mArpp gene contains nine exons and eight introns, spanning approximately $9 \mathrm{~kb}$ of the genome (Fig. 1E). We have already published the sequence of the mArpp gene in the DDBJ (accession no. AB079549). The translational start site and the stop codon were found to be located in exons 1 and 9 , respectively. These structural features of the mArpp gene are very similar to those of the hArpp gene (Miyazaki et al, 2002).

\section{Differential Expression of mArpp in Various Tissues}

The expression of mArpp in various mouse tissues was analyzed by Western blotting. As shown in Figure $2 \mathrm{~A}$, a single band corresponding to $43 \mathrm{kd}$ was detected in skeletal muscle (the brachial flexor). It was also detectable in brain, pancreas, and esophagus. The expression level in the brachial flexor muscle was high, whereas expression in the brain, pancreas, and esophagus was relatively low (Fig. 2A). Interestingly, mArpp expression was not evenly distributed, but varied in skeletal muscle from different body sites. As shown in Figure 2, B and C, the brachial flexor, diaphragm, and abdominal wall muscle expressed high levels of mArpp, whereas the brachial extensor, major pectoral muscle, crural flexor, and crural extensor expressed relatively low levels, and levels in the masseter and tongue were extremely low. Immunohistochemical analysis of selected skeletal muscles revealed that mArpp-positive and mArpp-negative muscle fibers were admixed in a checkerboard-like pattern (Fig. 3, A to D). In addition to mArpp-positive muscle fibers in which both the cytoplasm and the nuclei were positively immunostained, those in which the cytoplasm was positively stained but nuclei were unstained were also detectable (Fig. 3, E and F). Because the intensities of the mArpp immunoreactivities were not uniform, we categorized them into four groups: strongly immunoreactive $(+++)$, moderately immunoreactive $(++)$, weakly immunoreactive $(+)$, and nonimmunoreactive (-) (Fig. 3D). As shown in Figure 3G, the mArpp-positivity rate was high in the brachial flexor (69\%), relatively low in the brachial extensor (45.5\%), and very low in the masseter (17.7\%). Interestingly, although the number of muscle fibers with strong or moderate immunoreactivity was quite high in the brachial flexor $(45.4 \%)$, relatively low in the brachial extensor $(28.4 \%)$, and very low in the masseter (2.5\%), the number of weakly immunoreactive muscle fibers did not differ significantly among the brachial flexor (23.6\%), brachial extensor (17.1\%), and masseter $(15.2 \%)$. These findings suggest that differences in expression levels ämong mArpp-expressing skeletal muscles may be due to differences in the populations of muscle fibers that exhibit strong or moderate expression.

\section{mArpp is Expressed in the Brain, Pancreas, and} Esophagus, as well as in Skeletal Muscle

The expressions of mArpp in the brain, pancreas, and esophagus were analyzed by immunohistochemistry. In the cerebrum, both the nuclei and the cytoplasm of the neurons and some of the glial cells were immunostained (Fig. 4, A and C). Nonspecific immunoreactivity was considered unlikely because these positive immunoreactions were abolished when the anti-Arpp antibody $(\alpha-\operatorname{Arpp}[\mathrm{FL}] \mathrm{Ab})$ was preincubated with an excess of the immunogen (Fig. 4B). In the cerebellum, both the nucleus and the cytoplasm of Purkinje cells were positively immunostained, whereas the granular cells remained unstained (Fig. 4D). In the pancreas, strongly positive immunoreactivity was detectable in the nuclei but not in the cytoplasm of cells in the islets of Langerhans, and very weak immunoreactivity was detected in some of the exocrine acinar cells (Fig. 4, E and G). This nuclear restriction of mArpp expression was also seen in the squamous epithelium of the esophagus (Fig. 4H). These positive immunoreactivities were confirmed by absorption studies (Fig. 4, F 
A

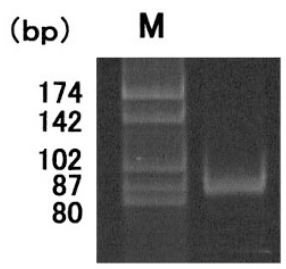

B
C

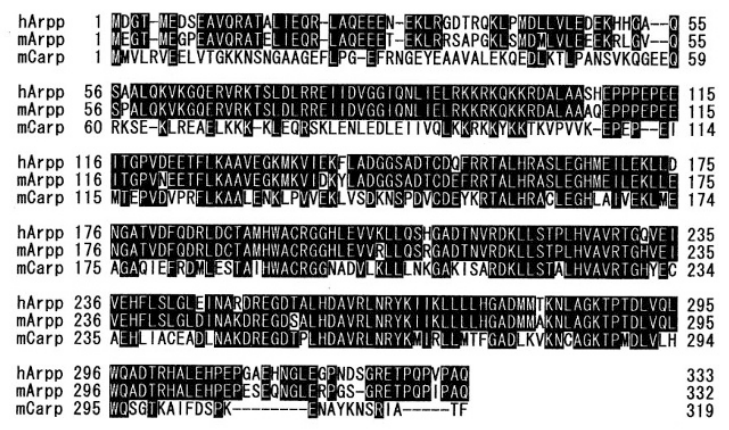

D

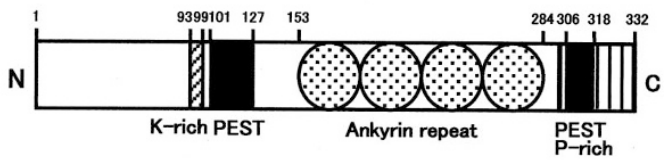

E

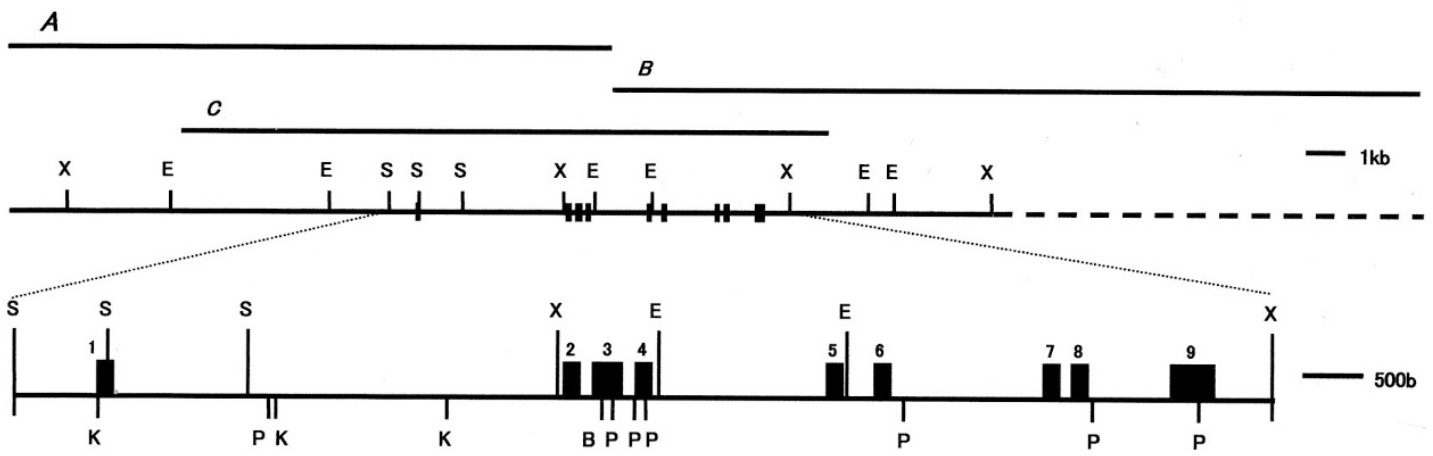

Figure 1.

Structure of the murine $\operatorname{Arpp}(m A r p p)$ gene and its protein. A, Identification of the transcriptional start site by the cap site hunting method. To amplify the mArpp cDNA containing the transcriptional initiation site, PCR was performed using the mouse skeletal muscle cap site cDNA as a template. The primer pair for the first round of PCR was a sense primer complementary to a synthetic oligoribonucleotide (rOligo) (1RDT) and an antisense primer complementary to the $m A$ rpp gene (R1) (see B). The primer pair for the second round of the nested PCR was a sense primer complementary to rOligo (2RDT) and an antisense primer complementary to the mArpp gene (R2) (see B). The product of the second round of the nested PCR was subjected to electrophoresis in $12 \%$ polyacrylamide gel. B, Sequence alignment of the mArpp cap site cDNA. The transcriptional start site is indicated by the vertical arrow. The positions of the primer pairs (1RDT and R1, and 2RDT and R2, respectively) are indicated by arrows. The synthetic rOligo sequence ligated to the mRNA is shown in italic lower case letters. $C$, Amino acid alignment of the human $\operatorname{Arpp}($ Arpp), mArpp, and cardiac-restricted ankyrin-repeat protein (Carp). The dark boxes show the conserved residues in the amino acid sequences. D, Schematic representation of the structure of mArpp protein. The four ankyrin-repeat domains, the two PEST sequences, the lysine-rich sequence, and the proline-rich region are indicated as dotted circles, black boxes, a hatched box, and a striped box, respectively. E, Structure of the mArpp gene. The nine exons of the mArpp gene are indicated by black boxes. The three lines at the top indicate the overlapping clones (clones $A, B$ and $C$ ) isolated from the mouse genomic library. $\mathrm{X}=X b a l, \mathrm{E}=E$ coRI, $\mathrm{S}=\mathrm{Sacl}, \mathrm{K}=\mathrm{Kpnl}, \mathrm{P}=\mathrm{Pstl}, \mathrm{B}=\mathrm{BamHI}$.

and I). Interestingly, mArpp-positive and mArppnegative cells were found to be admixed within normal esophageal epithelium. Furthermore, strongly immunoreactive cells tended to be localized in the basal layer, whereas the intermediate and superficial cells tended to exhibit weaker immunoreactivities (Fig. 4H). This nonuniform intensity of immunoreactivity among mArpp-positive cells suggests that mArpp may be down-regulated as the esophageal epithelial cells dif- ferentiate upward from the basal to the superficial layer.

\section{Arpp is Preferentially Expressed in Type 1 Skeletal Muscle Fibers}

The distributions of the mArpp-expressing muscle fibers were very similar to those of type 1 skeletal muscle fibers, leading us to hypothesize that the 
A
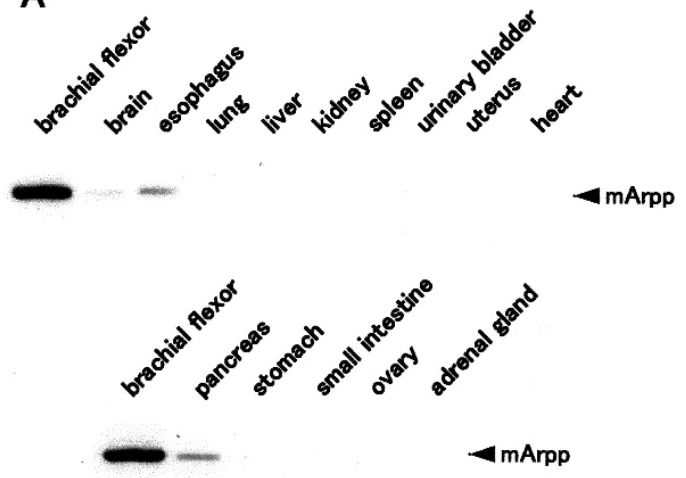

B

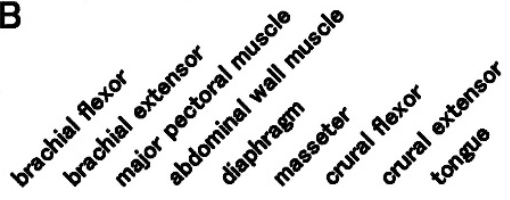

- - - - -
C

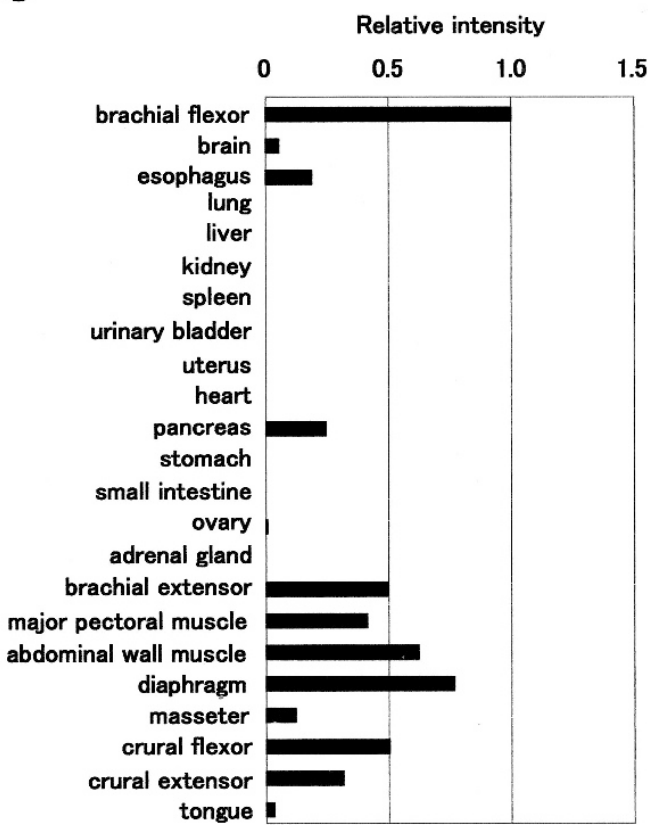

Figure 2.

Western blot analysis of mouse tissues for mArpp expression. A, Western blots of lysates of proteins (30- $\mu \mathrm{g}$ samples) extracted from various mouse tissues. B, To determine the expression levels of mArpp in skeletal muscle from various body sites, proteins extracted from the brachial flexor, brachial extensor, major pectoral muscle, abdominal wall muscle, diaphragm, masseter, crural flexor, crural extensor, and tongue ( $30-\mu \mathrm{g}$ samples) were subjected to Western blotting. $\mathrm{C}$, The relative intensities of the mArpp signals compared with the signal for the brachial flexor.

expression of mArpp may be type-specific. To test this hypothesis, one of two serial sections was subjected to immunohistochemistry with $\alpha$-Arpp(FL) $\mathrm{Ab}$ and the other was subjected to histochemistry with nicotinamide adenine dinucleotide tetrazolium reductase (NADH-TR) staining (Kremzier, 1984). As shown in Figure 4, J and $\mathrm{K}$, the mArpp-expressing fibers corresponded well with those that were stained dark blue by $\mathrm{NADH}-\mathrm{TR}$, suggesting that mArpp is preferentially expressed in type 1 muscle fibers. However, although most of the mArpp-positive muscle fibers were also positive for NADH-TR, small populations of NADH-TRpositive but mArpp-negative fibers were detectable (open arrowhead in Fig. 4K, solid arrowhead in Fig. 4J), suggesting that type 1 mouse skeletal muscle fibers do not always express mArpp.

\section{Intracellular Localization of Arpp in the Skeletal Muscle Fiber}

To determine the precise intracellular localization of mArpp protein in skeletal muscle, mouse abdominal skeletal muscle sections immunolabeled with $\alpha$-Arpp(FL) Ab were processed for immunoelectron microscopic observation. Immunoprecipitation for mArpp, which was recognized as vaguely-outlined electron-dense materials, covered over the I-band, but not over the A-band (Fig. 5A). Z-disc and its proximity was free of the immunoprecipitation. In control sections incubated with $\alpha$-Arpp(FL) Ab preabsorbed with an excess of the immunogen, the electron-dense materials were not seen at all on the muscle fibers (Fig. $5 \mathrm{~B})$. This immunoelectron microscopic observation suggests preferential expression of mArpp in the 1-band of skeletal muscle fibers.

Next, to determine whether this characteristic intracellular distribution pattern of Arpp in mice is also observed in humans, we performed immunofluorescence staining with $\alpha$-Arpp(FL) Ab on paraffinembedded human skeletal muscle. As shown in Figure 6 , A and D, hArpp was detectable in a doublet striation pattern in skeletal muscle. Coimmunostaining with a marker of the Z-disc structure, $\alpha$-actinin, revealed that hArpp was not colocalized with $\alpha$-actinin, although it was localized in close proximity to the Z-disc in skeletal muscle (Fig. 6, A, B, and C). Next, coimmunostaining with slow myosin heavy chain (slow MHC), which is localized in the A band, revealed that hArpp was not colocalized with slow MHC (Fig. 6, D, E, and $\mathrm{F})$, indicating that hArpp is not localized at the A band. These results suggest that Arpp is localized within the I-band adjacent to the Z-disc of skeletal muscle in both humans and mice.

\section{Marked Induction of mArpp and Carp in Denervated Skeletal Muscle}

It has been reported that some muscle-specific genes that participate in muscle morphogenesis are induced in denervated skeletal muscle (Arber et al, 1994; Baumeister et al, 1997; Eftimie et al, 1991). Because murine Carp is one example of such a gene (Baumeister et al, 1997), we investigated whether mArpp is also induced in denervated skeletal muscle. First, the expression of mArpp and Carp in denervated gastrocnemius muscle was analyzed by Western blotting. As 

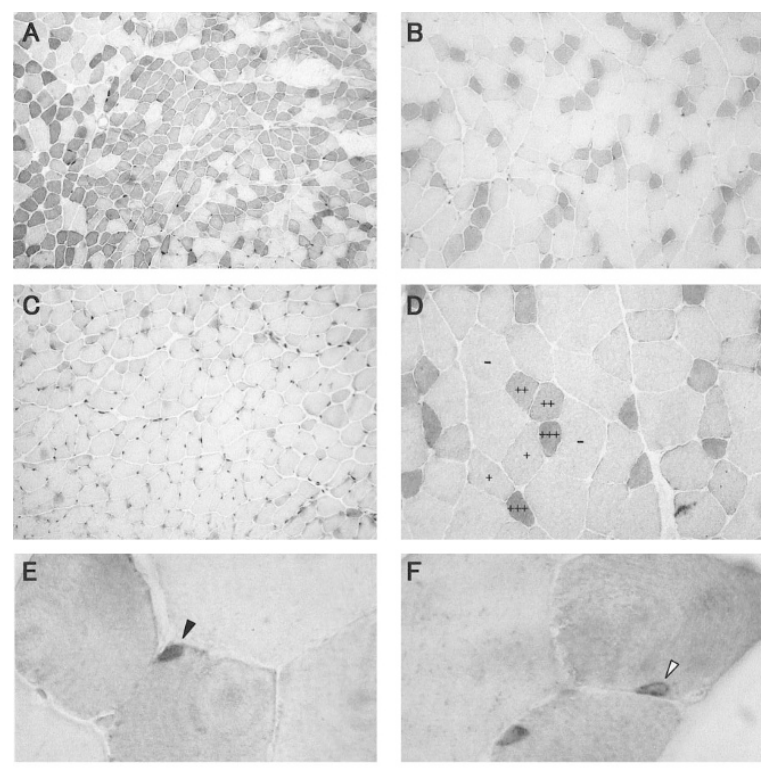

G

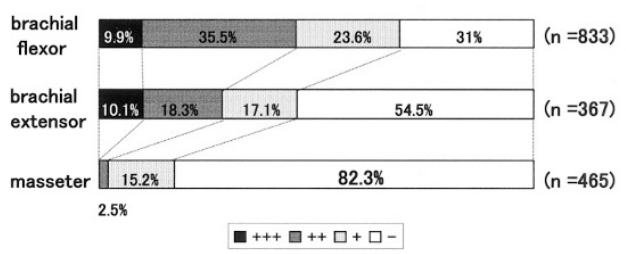

Figure 3.

Immunohistochemical analysis of skeletal muscles for mArpp. Frozen tissue sections of the brachial flexor $(A$; original magnification, $\times 100)$, brachial extensor $(B$; original magnification, $\times 100)$, and masseter $(C$; original magnification, $\times 100$ ) were subjected to immunohistochemistry with anti-Arpp antibody ( $\alpha$-Arpp[FL] Ab), as described in "Materials and Methods." We analyzed 833 muscle fibers from the brachial flexor, 367 from the brachial extensor, and 465 from the masseter, which were categorized into four groups according to the intensity of their immunoreactivity. Strongly immunoreactive $(+++)$, moderately immunoreactive $(++)$, weakly immunoreactive $(+)$, and nonimmunoreactive $(-)$ muscle fibers are illustrated in $D$ (original magnification, $\times 200$ ). Muscle fibers in which both the nucleus (solid arrowhead) and the cytoplasm were positively immunostained (E; original magnification, $\times 1,000)$ and those in which the cytoplasm was positive but the nucleus (open arrowhead) was negative for mArpp (F; original magnification, $\times 1,000)$ were admixed. G, Positivity rates for mArpp $(+++,++,+$, and -$)$ in the brachial flexor, brachial extensor, and masseter are shown.

shown in Figure 7A, although Carp was undetectable in nondenervated control muscle, its expression in denervated muscle was markedly up-regulated, peaked at 2 weeks after denervation, and was then down-regulated, becoming undetectable at 4 weeks after denervation. In contrast, mArpp was detectable in control muscle (Fig. 7A). Although the expression of mArpp was significantly up-regulated similarly to that of Carp at 1 week after denervation, its expression level remained constant for at least 4 weeks after denervation, in contrast to Carp (Fig. 7A). Next, the distributions of Carp-positive and mArpp-positive fibers in the denervated gastrocnemius and soleus muscles were analyzed by immunohistochemistry (Fig. 7B). In the nondenervated control muscle, although only a very small number of muscle fibers were found to express Carp (Fig. 7Ba), almost all of the muscle fibers of the soleus and only some of the gastrocnemius muscle fibers adjacent to the soleus were found to express mArpp (Fig. 7Bc). At 2 weeks after denervation, Carp-positive muscle fibers were found to be distributed throughout the gastrocnemius and soleus (Fig. 7Bb). Furthermore, as shown in Figure $7 \mathrm{Bd}$, at 3 weeks after denervation, mArpp-positive muscle fibers were also apparently increased and almost all of the muscle fibers of the gastrocnemius had become positive for mArpp. These findings suggest that both Carp and mArpp are markedly induced by denervation in muscle fibers that do not express Carp and mArpp under physiologic conditions.

\section{Discussion}

In this study, we isolated a murine cDNA clone that is highly homologous to hArpp cDNA. This murine gene is likely to be a counterpart of the hArpp gene, on the basis of the following findings. First, the nucleotide sequence of mArpp cDNA is highly homologous to that of hArpp cDNA (82.4\% identical) and, consequently, the mArpp gene encodes a protein homologous to hArpp in its amino acid sequence (88.9\% identical). The structural features of the hArpp protein, which contains ankyrin-repeat motifs, PEST sequences, and a proline-rich region, are well conserved in the mArpp protein, except for a PEST sequence in the C-terminal region. Second, we confirmed that both mArpp and hArpp exhibit similar expression patterns, with high levels of expression in type 1 fibers of skeletal muscle. Third, the arrangements of exons and introns in the hArpp and mArpp genes are very similar, although the sequence homology of each intron is significantly lower than that of each exon. Fourth, when hArpp was used as a probe, other homologous cDNA clones apart from the mArpp cDNA could not be isolated. Indeed, the five cDNA clones isolated in our study were all identical to mArpp cDNA.

Analysis using the DDBJ revealed that the cloned cDNA is almost identical to Arkrd2 cDNA, which was isolated as a mouse gene induced in stretched skeletal muscle (Kemp et al, 2000). Although the Ankrd2 gene was expected to encode an ankyrin-repeat protein composed of 328 amino acids (Kemp et al, 2000), in the present study mArpp was found to contain 332 amino acids. This discrepancy may be explained by the fact that the reported cDNA of Ankrd2 did not cover the full-length open reading frame and lacked the first methionine. Indeed, we determined the precise transcriptional start site by the cap site hunting method and found that the reported translational initiation codon of Ankrd2 corresponded to the second methionine of mArpp (Fig. 1A). We have shown in the present study that the first methionine of hArpp is conserved in mArpp. Furthermore, in a previous study, we have already confirmed that the first methionine of hArpp is preferentially used as a translational initiation site (Moriyama et al, 2001). Thus, it is likely that the first methionine of mArpp is used as a translational initiation codon. 

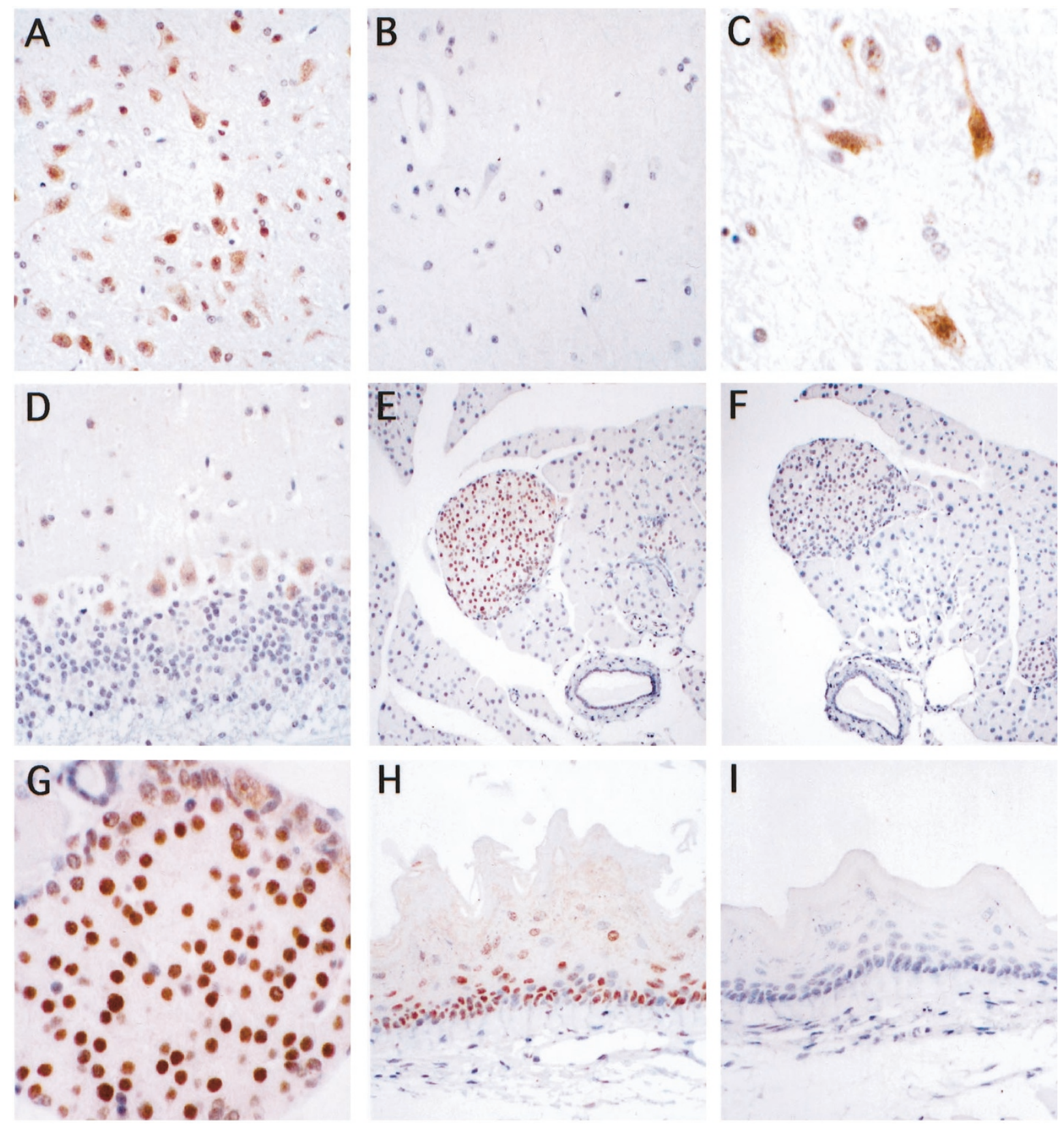

\section{H}
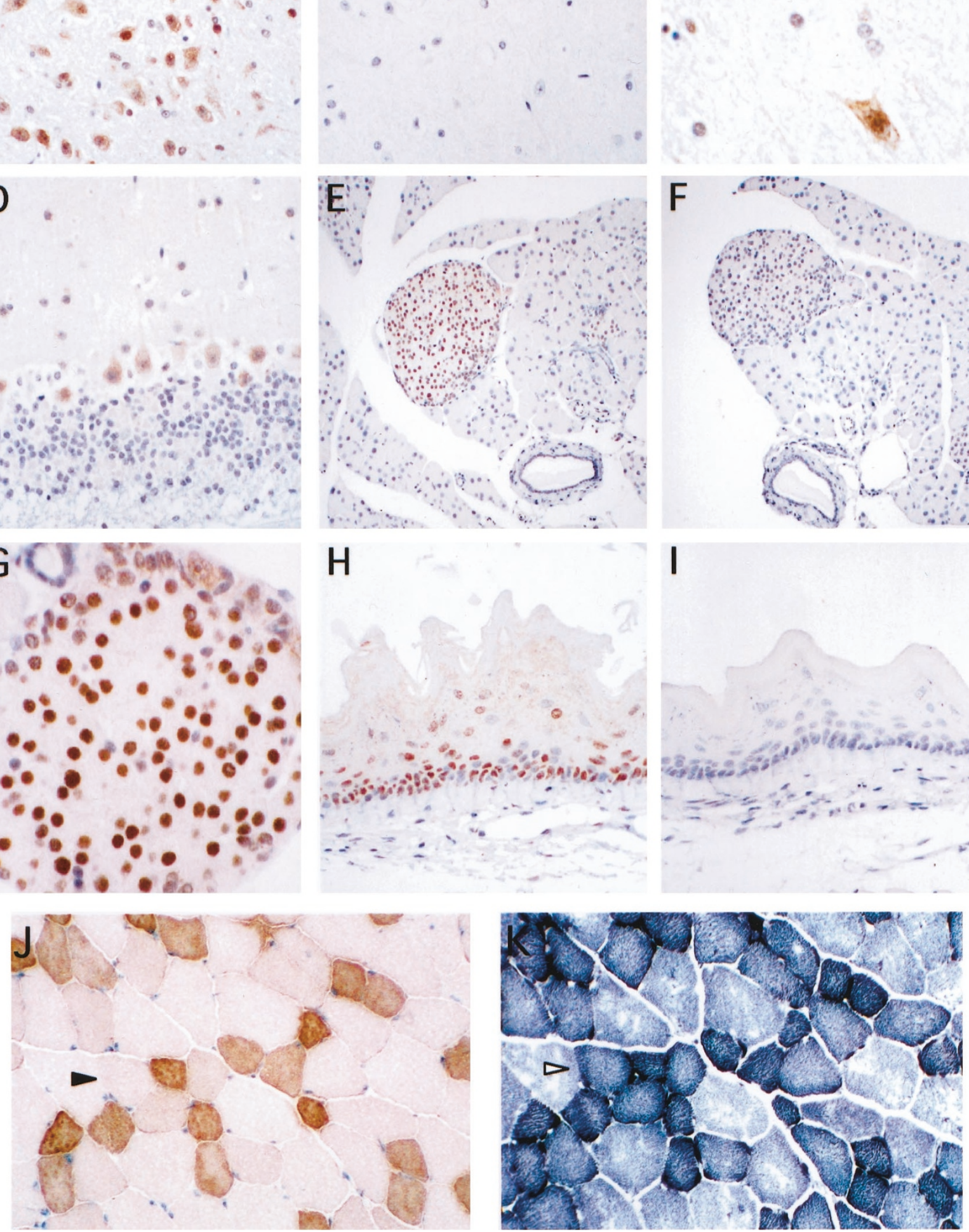

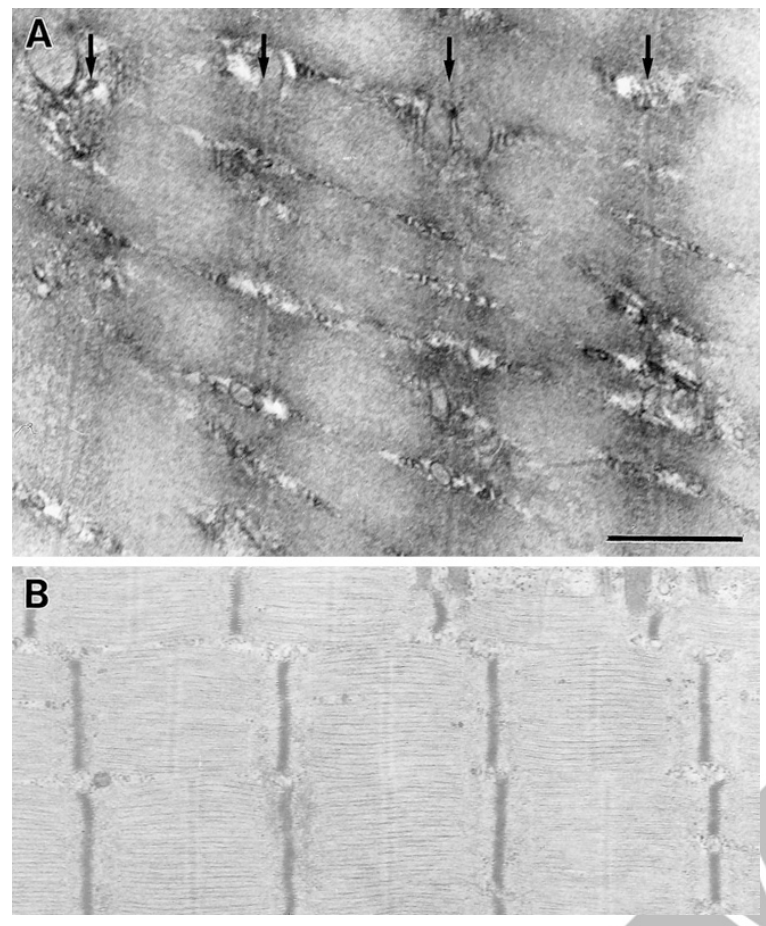

Figure 5.

Immunoelectron micrographs of skeletal muscle fibers with $\alpha$-Arpp(FL) Ab. A, The mouse skeletal muscle was subjected to the immunoelectron microscopy with $\alpha$-Arpp(FL) Ab as described in "Materials and Methods." The electrondense immunoprecipitation for mArpp covered over I-band, whereas A-band, Z-disc (arrows), and the area close to the Z-disc were free of immunoprecipitation. B, The electron-dense materials were not seen at all in the control sections incubated with the immunogen-preabsorbed $\alpha$-Arpp(FL) Ab. Scale bar, $1 \mu \mathrm{m}$.

Further analysis using the DDBJ revealed that the amino acid sequence of mArpp is also homologous (49.2\% identity) to that of the mouse gene, Carp, which is proposed to be a genetic marker for cardiac hypertrophy (Aihara et al, 2000; Zou et al, 1997). Because the structural features of mArpp, including four ankyrin motifs, PEST sequence, and nuclear localization signals, are well conserved in Carp, these two proteins are likely to be members of the same protein family and are also likely to be functionally related.

We have recently found that, in humans, Arpp protein is preferentially expressed in type 1 skeletal muscle fibers (Ishiguro, submitted). In this study, this was also found to be the case in mouse skeletal muscle, suggesting that Arpp may play important functional roles in type 1 skeletal muscle fibers in both humans and mice. Consistent with this hypothesis,
Arpp-positive fibers were frequently detectable in brachial flexor muscle, which is rich in type 1 fibers (data not shown), but were rarely detectable in masseter muscle, which is rich in type 2 muscle fibers (Tuxen and Kirkeby, 1990). The biologic function of Arpp in type 1 muscle fibers is largely unknown at this stage, and is an interesting issue to be addressed in future studies. However, it should be noted that all type 1 fibers do not necessarily express Arpp. Analysis of Arpp gene-disrupted mice may help us to answer this interesting question.

In skeletal muscle, Arpp was found to be localized in both the nucleus and the I-band of sarcomeres, suggesting that Arpp may function in the nucleus as well as in the sarcomeric I-band. However, the biochemical and biologic functions of Arpp in the nucleus and cytoplasm remain to be determined. Furthermore, it is also unclear how the intracellular localization of Arpp is regulated. It has recently been reported that the Arpp homolog, Carp, is also localized in both the nucleus and the sarcomeric I-band of cardiomyocytes (Bang et al, 2001; Zou et al, 1997). This intracellular localization pattern of Carp is very similar to that of Arpp. Interestingly, Carp was shown to be required for maintaining sarcomeric integrity via interaction in the cytoplasm with myopalladin, a recently identified protein localized at the sarcomeric I-band (Bang et al, 2001). In the nucleus, Carp was reported to be associated with a transcription factor, YB-1, and to regulate its transcriptional activity via the interaction (Zou et al, 1997). Thus, these close similarities between Arpp and Carp in protein structure and intracellular localization pattern lead us to speculate that Arpp may exhibit functions in skeletal muscle similar to those of Carp in heart.

We detected mArpp at the protein level not only in skeletal muscle but also in brain, pancreas, and esophagus, although mArpp was undetectable in brain, pancreas, and esophagus at the mRNA level by Northern blot analysis (data not shown). The discrepancy between the data from Northern blot analysis and those from Western blot analysis may be partly explained by the stability of the mArpp protein. Indeed, we recently found that Arpp protein is very stable, with a very long half-life (up to 48 hours) in HeLa cells that transiently overexpressed hArpp protein (Nakada, unpublished observation). Furthermore, we also found that the intracellular localization of mArpp is different among tissues expressing mArpp. In skeletal muscle and brain, mArpp was expressed in both the nuclei and cytoplasm, whereas in pancreas

\section{Figure 4.}

Expression of mArpp in various tissues. Paraffin-embedded tissue sections from the cerebrum immunostained with $\alpha$-Arpp(FL) Ab (A; original magnification, $\times 200$. $\mathrm{C}$; original magnification, $\times 00$ ) or with $\alpha$-Arpp(FL) Ab that had been preincubated with an excess of the immunogen (B; original magnification, $\times 200)$. A section of the cerebellum immunostained with $\alpha$-Arpp $(F L) A b(D$; original magnification, $\times 200)$. One of a set of serial sections of the pancreas was immunostained with $\alpha$-Arpp $(\mathrm{FL}) \operatorname{Ab}(\mathrm{E}$; original magnification, $\times 200)$, and the other was immunostained with $\alpha$-Arpp(FL) Ab that had been preincubated with an excess of the immunogen (F; original magnification, $\times 200$ ). A high-power view of an islet of Langerhans in the pancreas immunostained with $\alpha$-Arpp(FL) Ab (G; original magnification, $\times 400$ ). A section of the esophagus was immunostained with $\alpha$-Arpp(FL) Ab $(\mathrm{H}$; original magnification, $\times 200)$ or with $\alpha$-Arpp(FL) Ab that had been preincubated with an excess of the immunogen (l; original magnification, $\times 200$ ). Finally, localization of mArpp-expressing muscle fibers and NADH-TR-positive muscle fibers within skeletal muscle was analyzed. One of a pair of serial sections of frozen brachial extensor tissue was immunostained with $\alpha$-Arpp(FL) Ab (J; original magnification, $\times 200$ ); the other was stained with NADH-TR $(\mathrm{K}$; original magnification, $\times 200)$. 


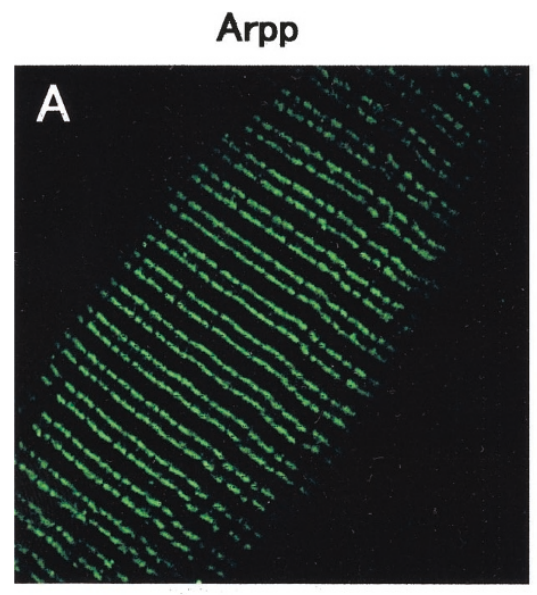

Arpp

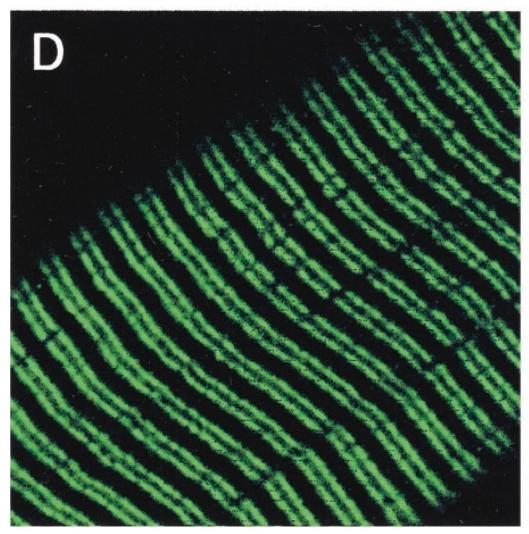

Figure 6.

Confocal images of double immunostaining with $\alpha$-Arpp(FL) Ab and anti- $\alpha$-actinin Ab or $\alpha$-slow myosin heavy chain (MHC) Ab. Paraffin-embedded tissue sections from human skeletal muscle were analyzed by double immunostaining analysis with $\alpha$-Arpp(FL) Ab together with anti- $\alpha$-actinin $\mathrm{Ab}$ or $\alpha$-MHC (slow) Ab as the first antibody, and then incubated with a mixture of Alexa Fluor 488-conjugated goat anti-rabbit secondary antibody (green) and Alexa Fluor 546-conjugated goat anti-mouse secondary antibody (red). Arpp was detected as a green signal (A and D). $\alpha$-Actinin (B) and slow MHC (E) were detected as a red signal. When both the green signals and the red signals were merged, yellow signals reflecting coexpression of Arpp and $\alpha$-actinin or slow MHC were not detected (C and F).

and esophagus, mArpp expression was restricted to the nuclei. This observation suggests that the intracellular localization of mArpp is regulated in a tissuespecific manner.

a

In this study, we found that the expressions of both Carp and mArpp in skeletal muscle were markedly induced after denervation. This observation is consistent with the previous report that the level of Carp mRNA is up-regulated in denervated skeletal muscle as well as in embryonic skeletal muscle (Baumeister et al, 1997). It has been reported that Carp is required for maintaining sarcomeric integrity via interaction in the cytoplasm with myopalladin (Bang et al, 2001). These findings suggest that Carp may play a specific functional role in denervated skeletal muscle. Although the functional roles of mArpp in skeletal muscle remain unclear, close similarities between Arpp and Carp in their protein structure and intracellular localization pattern suggest that Arpp may also play some role in maintenance of sarcomeric structure. On the other hand, the expression patterns of Carp and Arpp in denervated muscle are quite different in that the level of induced mArpp remains constant for 4 weeks after denervation, whereas the level of induced Carp is markedly down-regulated and finally becomes undetectable at 4 weeks after denervation. These results suggest that the biologic functions of Carp and Arpp in denervated muscle are not completely the same. Further studies will be needed to address these interesting questions.

\section{Materials and Methods}

\section{Antibodies}

Anti-Carp antibody ( $\alpha$-Carp[N] Ab) recognizing the $\mathrm{N}$-terminal 69 amino acids of mouse Carp protein was generated as follows. The cDNA encoding the $\mathrm{N}$-terminal region of mouse Carp was amplified by PCR with the forward primer, 5'-TGGATCCACATGATGGTACTGAGAGTAGAG-3' and the reverse primer, 5'TCTCGAGTCACTCTGCCTCTCGCAGTTTC-3' using the mouse heart cDNA library as a template. The resulting PCR products were cloned and sequenced. The cloned PCR products were then ligated into pGEX5X-1 vector plasmid (Amersham-Pharmacia Biotech, Buckinghamshire, United Kingdom) and the N-terminal Carp protein fused to glutathione S-transferase (GST-Carp) 
A

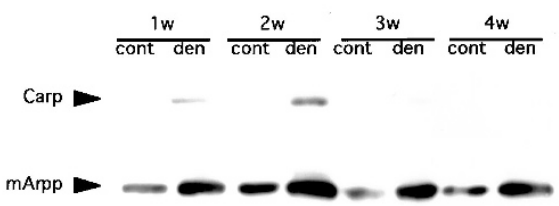

B
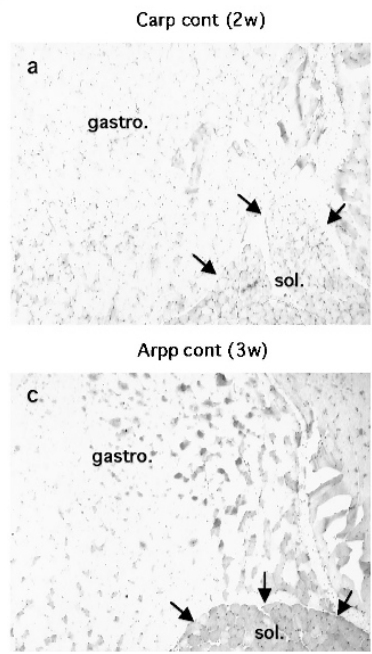

Figure 7.

Induction of Carp and mArpp in denervated skeletal muscle. A, Western blot analysis of Carp and mArpp expression in denervated left gastrocnemius muscles (den) at 1, 2, 3, and 4 weeks after denervation ( $1 w, 2 w, 3 w$, and $4 w)$. Right gastrocnemius muscles were used as the controls (cont). B, Immunohistochemistry for Carp and mArpp expression in denervated muscles (den). Frozen sections of denervated gastrocnemius (gastro.) and soleus (sol.) muscles and their control muscles (cont) at 2 weeks (2w) and 3 weeks (3w) after denervation were immunostained with anti-Carp antibody ( $a$ and $b$ ) or $\alpha$-Arpp(FL) Ab (c and d), respectively. Arrows indicate the margin of the soleus muscle. Original magnification, $\times 40$.

was synthesized in E. coli, as described previously (Onizuka et al, 1995). Then, the purified GST-Carp protein was used to immunize rabbits to raise $\alpha$-Carp(N) Ab. The antibody was affinity-purified as described previously (Moriyama et al, 2001). Rabbit polyclonal $\alpha$-Arpp(FL) Ab used in this study has been characterized and described in detail previously (Moriyama et al, 2001).

\section{Animals}

Female C57BL/6 mice were purchased from Japan SLC (Shizuoka, Japan). All of the animals were 10 weeks of age at the start of the experiment. They were anesthetized by intraperitoneal injection of ketamine $(50 \mathrm{mg} / \mathrm{kg})$ and xylazine $(5 \mathrm{mg} / \mathrm{kg}$ ). All experiments were performed in accordance with the guidelines of animal care and use established by the Tottori University (Permission No. 01-S-44). Under the anesthetic condition, the left sciatic nerve was surgically cut. At 1 , 2,3 , and 4 weeks after denervation, the right and left gastrocnemius and soleus muscles were resected and then subjected to the following experiments. The right gastrocnemius and soleus muscles of each mouse were used as their own controls.

\section{Construction and Screening of the cDNA Library}

A cDNA library was constructed from mouse skeletal muscle with the ZAP cDNA Gigapack III Gold Cloning kit (Stratagene, La Jolla, California) according to the manufacturer's instructions. For the first screening, $1.0 \times 10^{6}$ pfu was incubated with XL1 Blue MRF' host cells, and the mixture was plated onto NZY-agar plates. After incubation at $37^{\circ} \mathrm{C}$ for several hours, nylon filters (Hybond $\mathrm{N}^{+}$; Amersham Pharmacia BioTech, Tokyo, Japan) were placed onto the plates. The resulting replica filters were hybridized with hArpp cDNA labeled with [ $\left.{ }^{32} \mathrm{P}\right] \mathrm{dCTP}$ in a hybridization buffer containing $6 \times$ SSC, $5 \times$ Denhardt's solution, $0.5 \%$ $\mathrm{w} / \mathrm{v}$ SDS, and $20 \mu \mathrm{g} / \mathrm{ml}$ salmon sperm DNA at $65^{\circ} \mathrm{C}$ for 8 hours, washed twice with $0.2 \times \mathrm{SSC}$ at $65^{\circ} \mathrm{C}$ for 30 minutes, and autoradiographed. The second and third screenings were performed in the same way. Any positive clones were subjected to in vivo excision with the ZAP cDNA Gigapack III Gold Cloning kit (Stratagene) according to the manufacturer's instructions. The pBluescript SK phagemid containing the cDNA of interest was then sequenced.

\section{Screening of the Mouse Genomic Library}

Mouse genomic library (Stratagene; $0.8 \times 10^{6} \mathrm{pfu}$ ) was screened with hArpp cDNA as a probe. XL1 Blue MRA cells were used as the host. Hybridization and stringent washing were performed as for the screening of the cDNA library.

\section{Determination of the Transcriptional Start Site}

Mouse skeletal muscle cap site cDNA was purchased from Nippon Gene (Toyama, Japan). The procedure for the synthesis of cap site CDNA has been described in detail by Maruyama and Sugano (1994). Briefly, the cap structure of mRNA was removed with tobacco acid pyrophosphatase (TAP) after treatment with alkaline phosphatase. Subsequently, a synthetic oligoribonucleotide (rOligo) was ligated to the 5'-terminus of the decapped mRNA by using T4 RNA ligase. The ligated mRNA was then converted to cDNA with reverse transcriptase and oligo(dT) as a primer. In this study using mouse skeletal muscle cap site cDNA, a nested PCR was performed to amplify the mArpp cDNA containing the transcriptional initiation site of the gene. The primer set for the first PCR consisted of a forward primer complementary to rOligo (1RDT; 5'-GATGCTAGCTGCGAGTCAAGTC-3') and a reverse primer complementary to mArpp cDNA (R1; 5'-CTCAGTCTCTTCCTCCTGGGCAAGCCGC-3'). The primer set for the nested PCR comprised a forward primer complementary to rOligo (2RDT; 5'-CGAGTCAAGTCGACGAAGTGC-3') and a reverse primer complementary to mArpp cDNA (R2; 5'-GATGAGCTCTGTGGCTCTCTGCACC-3'). PCR was performed according to the manufacturer's instructions.

\section{Western Blotting}

The tissues of interest were lysed on ice for 90 minutes in SDS-modified RIPA buffer $(0.1 \% \mathrm{w} / \mathrm{v}$ SDS; $40 \mathrm{~mm}$ 
HEPES-NaOH, pH 7.4; $1 \%$ v/v Nonidet P-40, NP40; $0.5 \% \mathrm{w} / \mathrm{v}$ sodium deoxycholate; $150 \mathrm{~mm} \mathrm{NaCl} ; 1 \mathrm{~mm}$ phenylmethylsulfonyl fluoride; $10 \mathrm{~mm}$ sodium pyrophosphate; $10 \mathrm{~mm}$ sodium fluoride; $4 \mathrm{~mm}$ EDTA; and 2 mM sodium vanadate), then centrifuged at $15,000 \mathrm{rpm}$ at $4^{\circ} \mathrm{C}$ for 20 minutes. The resulting cell lysates $(30 \mu \mathrm{g}$ samples) were boiled with Laemmli's sample buffer and subjected to SDS (10\% w/v)-polyacrylamide gel electrophoresis. The samples were transferred to a polyvinylidene difluoride membrane (Millipore, Bedford, Massachusetts), which was blocked for 1 hour in $10 \% \mathrm{w} / \mathrm{v}$ skim milk in $1 \times$ Tris-buffered saline (TBS) at $4^{\circ} \mathrm{C}$, then incubated for 1 hour at $4^{\circ} \mathrm{C}$ with $1 \mu \mathrm{g} / \mathrm{ml}$ $\alpha$-Arpp(FL) Ab or $\alpha$-Carp(N) Ab. The filter was washed thoroughly with $1 \times$ TBS containing $0.1 \% \mathrm{v} / \mathrm{v}$ Tween 20 , then incubated for 1 hour at $4^{\circ} \mathrm{C}$ with a donkey anti-rabbit IgG horseradish peroxidase-linked whole antibody (Amersham-Pharmacia Biotech) and rewashed with $1 \times$ TBS containing $0.1 \% \mathrm{v} / \mathrm{v}$ Tween 20 . Finally, the signals were detected with the ECL Western blotting analysis system (Amersham-Pharmacia Biotech) according to the manufacturer's instructions.

\section{Immunohistochemistry}

Paraffin-embedded tissue sections were prepared as follows. Mouse brain, pancreatic, and esophageal tissues were fixed in $10 \%$ formalin for 12 hours, dehydrated with ethanol, and embedded in paraffin after progressive xylene washes. Before use, the tissue sections were thoroughly deparaffinized and rehydrated by the use of standard protocols. For antigen retrieval, the sections were immersed in $10 \mathrm{~mm}$ sodium citrate buffer ( $\mathrm{pH}$ 6.0) (latron, Tokyo, Japan), autoclaved at $120^{\circ} \mathrm{C}$ for 10 minutes and cooled to room temperature (RT). They were then treated with $3 \%$ $\mathrm{H}_{2} \mathrm{O}_{2}$ for 5 minutes at RT to inactivate endogenous peroxidase activity, and blocked with $10 \%$ goat serum (Nichirei, Tokyo, Japan) for 20 minutes at RT.

Frozen tissue sections were prepared as follows. Skeletal muscle tissues from various body sites were snap-frozen in isopentane cooled in liquid nitrogen, then tissue sections were prepared with a cryostat. After fixation in acetone at $-20^{\circ} \mathrm{C}$ for 1 hour, these sections were washed with $1 \times$ PBS, treated with $3 \%$ $\mathrm{H}_{2} \mathrm{O}_{2}$ for 10 minutes at RT, and blocked with $10 \%$ goat serum (Nichirei) for 20 minutes at RT.

Subsequently, immunohistochemistry with $\alpha$-Arpp(FL) Ab or $\alpha-\operatorname{Carp}(\mathrm{N}) \mathrm{Ab}$ of the tissue sections prepared as described above was performed as follows. Tissue sections were incubated with $\alpha$-Arpp(FL) Ab or $\alpha$-Carp $(\mathrm{N})$ $\mathrm{Ab}$ diluted to 1:5000 with diluting solution (DAKO, Carpinteria, California) for 18 hours at $4^{\circ} \mathrm{C}$. The sections were then washed with $1 \times$ PBS and incubated for 20 minutes with biotinylated goat anti-rabbit lgG (Nichirei). After being washed with $1 \times$ PBS, they were incubated with a solution of avidin-conjugated horseradish peroxidase (Vectastain Elite ABC kit; Vector Laboratories, Burlingame, California) for 10 minutes, according to the manufacturer's recommendations, then washed again with $1 \times$ PBS for 5 minutes. Peroxidase activity was detected with $\mathrm{H}_{2} \mathrm{O}_{2}$ /diaminobenzidine (DAB) substrate solution and the sections were counter-stained with hematoxylin before dehydration and mounting.

\section{Double-Labeled Immunohistochemistry (Arpp Versus $\alpha$-Actinin or Slow MHC)}

Deparaffinized sections of human skeletal muscle were immersed in $10 \mathrm{~mm}$ sodium citrate buffer $(\mathrm{pH} 6.0)$ (latron) and autoclaved at $120^{\circ} \mathrm{C}$ for 10 minutes. Subsequently, they were blocked with $10 \%$ normal goat serum (Nichirei) for 20 minutes at RT. The sections were then incubated for 18 hours at $4^{\circ} \mathrm{C}$ with a mixture of $\alpha-\operatorname{Arpp}(\mathrm{FL})$ Ab diluted to 1:2,000 and one of the following first antibodies: anti- $\alpha$-actinin Ab diluted to $1: 400$ or $\alpha$-slow MHC Ab diluted to $1: 50$. The sections were washed with $1 \times$ PBS and incubated for 2 hours at RT with a mixture of Alexa Fluor 488conjugated goat anti-rabbit antibody diluted to 1:200 and Alexa Fluor 546-conjugated goat anti-mouse antibody (Molecular Probes, Eugene, Oregon) diluted to 1:200 in $1 \times$ PBS. The sections were then washed with $1 \times$ PBS and mounted with $\mathrm{gel} / \mathrm{mount}$ (Biomedia, Foster City, California). The mounted sections were observed with a fluorescence microscope (Eclipse E800; Nikon, Tokyo, Japan), and the images were processed with the MRC-1024 confocal system (BioRad, Hercules, California).

\section{Histochemistry (NADH-TR)}

Histochemistry for NADH-TR activity was performed as follows. Cryosections of skeletal muscles were first air-dried for 1 hour. They were then incubated in 0.05 $\mathrm{M}$-Tris- $\mathrm{HCl}$ buffer $(\mathrm{pH} 7.4)$ containing $1 \mathrm{mg} / \mathrm{ml}$ nitro blue tetrazolium (NBT) and $0.8 \mathrm{mg} / \mathrm{ml} \beta$-nicotinamide adenine dinucleotide $(\bar{\beta}-\mathrm{NADH})$ at $37^{\circ} \mathrm{C}$ for $30 \mathrm{~min}-$ utes. The sections were then destained using $60 \%$, $90 \%$, and $60 \%$ acetone solutions in that order. Finally, they were rinsed in deionized water, and then mounted with coverslips and aqueous mounting medium.

\section{Immunoelectron Microscopy}

Cryosections of the paraformaldehyde-fixed mouse skeletal muscle were incubated at RT for 2 hours with $\alpha$-Arpp(FL) Ab diluted to 1:300 in 1XPBS, and then incubated with biotinylated anti-rabbit $\lg$ antibody, avidin-biotin-peroxidase complex, and with diaminobenzidine solution. The sections were then postfixed with osmic acid, dehydrated, and embedded in epoxy resin. Ultrathin sections were cut with an ultramicrotome, and observed under a transmission electron microscope (100CX; JEOL, Tokyo, Japan). Control sections were incubated with $\alpha-\operatorname{Arpp}(\mathrm{FL}) \mathrm{Ab}$ preabsorbed with an excess of the immunogen.

\section{References}

Aihara Y, Kurabayashi M, Saito Y, Ohyama Y, Tanaka T, Takeda S, Tomaru K, Sekiguchi K, Arai M, Nakamura T, and Nagai R (2000). Cardiac ankyrin repeat protein is a novel marker of cardiac hypertrophy: Role of M-CAT element within the promoter. Hypertension 36:48-53. 
Arber S, Halder G, and Caroni P (1994). Muscle LIM protein, a novel essential regulator of myogenis, promotes myogenic differentiation. Cell 79:221-231.

Bang ML, Mudry RE, McElhinny AS, Trombitas K, Greach AJ, Yamasaki R, Sorimachi H, Granzier H, Gregorio CC, and Labeit S (2001). Myopalladin, a novel 145-kilodalton sarcomeric protein with multiple roles in Z-disc and I-band protein assemblies. J Cell Biol 153:413-427.

Baumeister A, Arber S, and Caroni P (1997). Accumulation of muscle ankyrin repeat protein transcript reveals local activation of primary myotube endcompartments during muscle morphogenesis. J Cell Biol 139:1231-1242.

Chu W, Burns DK, Swerlick RA, and Presky DH (1995). Identification and characterization of a novel cytokineinducible nuclear protein from human endothelial cells. J Biol Chem 270:10236-10245.

Eftimie R, Brenner H, and Buonanno A (1991). Myogenin and MyoD join a family of skeletal muscle genes regulated by electrical activity. Proc Natl Acad Sci USA 88:1349-1353.

Jeyaseelan R, Poizat C, Baker RK, Abdishoo S, Isterabadi LB, Lyons GE, and Kedes L (1997). A novel cardiac-restricted target for doxorubicin. CARP, a nuclear modulator of gene expression in cardiac progenitor cells and cardiomyocytes. J Biol Chem 272:22800-22808.

Kemp TJ, Sadusky TJ, Saltisi F, Carey N, Moss J, Yang SY, Sassoon DA, Goldspink G, and Coulton GR (2000). Identification of Ankrd2, a novel skeletal muscle gene coding for a stretch-responsive ankyrin-repeat protein. Genomics 66: $229-241$.

Kremzier JE (1984). Histochemistry of muscle. In: Heffner Jr RR, editor. Muscle pathology. New York: Churchill Livingstone, 31-42.
Kuo H, Chen J, Ruiz-Lozano P, Zou Y, Nemer M, and Chien KR (1999). Control of segmental expression of the cardiacrestricted ankyrin repeat protein gene by distinct regulatory pathways in murine cardiogenesis. Development 126:42234234.

Maruyama K and Sugano S (1994). Oligo-capping: A simple method to replace the cap structure of eukaryotic mRNAs with oligoribonucleotides. Gene 138:171-174.

Miyazaki A, Tsukamoto $\mathrm{Y}$, Sato K, Ohgi S, and Moriyama M (2002). Genomic organization of the human Arpp gene. Yonago Acta Medica 45:1-8.

Moriyama M, Tsukamoto Y, Kondo G, Fujiwara M, Nakada C, Baba T, Ishiguro N, Miyazaki A, Nakamura K, Hori N, Sato K, Shomori K, Takeuchi K, Satoh H, Mori S, and Ito H (2001). Identification of a novel human ankyrin-repeated protein homologous to CARP. Biochem Biophys Res Comm 285: 715-723.

Onizuka T, Moriyama M, Yamochi T, Kuroda T, Kazama A, Kanazawa N, Sato K, Kato T, Ota H, and Mori S (1995). BCL-6 gene product, a 92- to 98-kd nuclear phosphoprotein, is highly expressed in germinal center B cells and their neoplastic counterparts. Blood 86:28-37.

Tuxen A and Kirkeby S (1990). An animal model for human masseter muscle: Histological characterization of mouse, rat rabbit, cat, dog, pig and cow masseter muscle. J Oral Maxillofac Surg 48:1063-1067.

Zou Y, Evans S, Chen J, Kuo H-C, Harvey RP, and Chien KR (1997). CARP, a cardiac ankyrin repeat protein, is downstream in the $N k x 2-5$ homeobox gene pathway. Development 124:793-804.

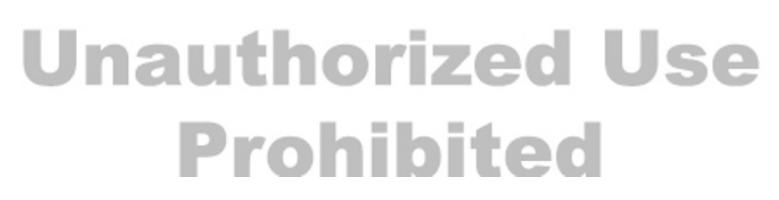

